\title{
Correction to: Mind, Brain, and Behavior: an Integrative Approach to Teaching Neuroscience to Medical Students
}

Arden D Dingle ${ }^{1}$ (D) Annelyn Torres-Reveron ${ }^{1} \cdot$ Mario Gil $^{1} \cdot$ Francisco Fernandez $^{1} \cdot$ Ignacio Martinez Escobedo $^{2}$. Valerie Terry $^{1}$. Gladys E Maestre ${ }^{1} \cdot$ Gabriel A de Erausquin ${ }^{1}$

Published online: 24 July 2019

(C) Academic Psychiatry 2019

\section{Correction to: Academic Psychiatry} https://doi.org/10.1007/s40596-019-01079-x

This article was updated to correct Ignacio Martinez Escobedo's name.

Publisher's Note Springer Nature remains neutral with regard to jurisdictional claims in published maps and institutional affiliations.

The online version of the original article can be found at https://doi.org/ 10.1007/s40596-019-01079-x

$\triangle$ Arden D Dingle adingle@emory.edu

1 University of Texas Rio Grande Valley School of Medicine, Harlingen, TX, USA

2 Texas Southmost College, Brownsville, TX, USA 